\title{
Edgar Allan Poe, heteronômio de Baudelaire?
}

Edgar Allan Poe, Baudelaire's heteronym?

\author{
Álvaro Cardoso Gomes*
}

\begin{abstract}
RESUMO
Este artigo estuda as relações entre Edgar Allan Poe e Charles Baudelaire, tentando mostrar que o escritor francês, grande admirador do autor americano, numa série de ensaios encomiásticos, acabou por compor uma espécie de "alta vulgarização" do primeiro, no dizer do crítico P. Mansell Jones. Desse modo, Baudelaire irá expressar o que Harold Bloom cunhou de "anxiety of influence", como se Poe se tornasse um seu heterônimo

Palavras-chave: Poe, Baudelaire, biografia.
\end{abstract}

\begin{abstract}
This article studies the relationships between Edgar Allan Poe and Charles Baudelaire, trying to show that the French writer, great admirer of the American author, in a series of essays, turned out to compose a kind of "high popularization" of the first, in the words of critic P. Mansell Jones. Thus, Baudelaire will express what Harold Bloom called the "anxiety of influence", as Poe became his heteronym.
\end{abstract}

Keywords: Poe, Baudelaire, biography.

* UNISA - Universidade de Santo Amaro 
A importância da obra de Edgar Allan Poe para o Simbolismo já é sobejamente conhecida. Edward Shanks considera o poeta americano como "o verdadeiro pai daquele movimento que varreu a Europa no fim do século XIX e que é descrito às vezes como 'Decadentismo' e às vezes como 'Simbolista'” (1937, p. 58). Mas houve críticos que superestimaram a influência de Poe sobre o Simbolismo: uns chegaram a ver Poe como o primeiro simbolista e outros, a exemplo de Charles Cestre, afirmaram sem hesitação que Poe e Baudelaire "se assemelham porque pertencem ao mesmo movimento literário (sic) e sofreram as mesmas influências" (1934, p. 323). Um crítico mais cuidadoso como Edmund Wilson reconhece a importância de Poe, a ponto de chamá-lo de "profeta" do Simbolismo, mas sem chegar ao exagero das afirmações tanto de Shanks quanto Cestre. Em sua obra já clássica Axel's Castle, o crítico americano afirma que os "critical writings" de Poe, acima de tudo, providenciaram

as primeiras escrituras do Movimento Simbolista, porque ele havia formulado o que era fundamental para um novo programa literário que corrigia a frouxidão e as extravagâncias românticas" (WILSON, 1993, p. 17).

Poe, além de evitar a frouxidão e as extravagâncias românticas, com um rigoroso controle do fazer poético, ainda propôs algo que, a nosso ver, é a base da estética simbolista, a indefinição em poesia. Isso tudo era original num país como a França, cujo Romantismo, via de regra, dominado pelo confessionalismo, tendia à expressão direta dos sentimentos. Nos Estados Unidos, contudo, como bem observa Edmund Wilson, escritores românticos como Poe, Hawthorne, Melville, Withman e mesmo Emerson estavam, por razões que seria importante determinar, progredindo na direção do Simbolismo. Neste país pode-se então dizer que aconteceu um Simbolismo avant la lettre e isso explica, em parte, a pouca admiração que Poe provocou em sua terra natal e na Inglaterra e o furor com que foi recebido na França.

Mas não nos interessa nos limites deste ensaio tratar das influências de Poe sobre os simbolistas franceses no geral; interessa-nos isto sim saber por que Poe exerceu tão grande atração sobre Baudelaire, a ponto de este dedicar 15 anos de seu precioso tempo para lhe traduzir a obra e divulgá-la na França. A justificativa para tal atração se encontra ao longo das cartas dirigidas a críticos, poetas, a sua própria mãe e dos ensaios que dedicou a Poe. Numa carta de 1858 ao crítico Armand Fraisse, Baudelaire diz o seguinte: 
Em 1846 ou 1847, fiquei familiarizado com uns poucos fragmentos de Edgar Poe. Experimentei uma emoção peculiar. Como suas obras completas somente foram reunidas depois de sua morte, numa única edição, tive a paciência de fazer amizade com alguns americanos que viviam em Paris, de modo a poder emprestar deles coleções de periódicos que haviam sido editados por Poe. E então achei, acredite se quiser, poemas e narrativas sobre os quais tinha uma vaga, confusa e mal formada ideia, e para os quais Poe tinha sabido como organizar e levar à perfeição (1907, p. 176).

Seis anos antes, Baudelaire havia escrito à mãe (27 de março de 1852), contando a estranha impressão que Poe lhe causara e aproximando sua vida da vida do escritor americano:

Descobri um autor americano pelo qual me sinto incrivelmente atraído; escrevi dois artigos sobre sua vida e obras. Foram escritos com entusiasmo, mas você sem dúvida encontrará neles algumas indicações de uma extraordinária excitação. Este é o resultado do sofrimento e da vida louca que estou levando (1957, p. 66).

O fascínio exercido por Edgar Allan Poe sobre Baudelaire excitou tanto alguns críticos que estes chegaram a ver entre ambos uma profunda fraternidade. É o caso de Charles Cestre. No ensaio encomiástico que dedicou a ambos, o crítico francês parece impregnar-se da aura romântica que envolve os dois poetas e acaba por projetar neles uma imagem estereotipada do gênio nevrótico, incompreendido e condenado a uma solidão criadora:

É de início, num e noutro, essa constituição física análoga, e podemos reconhecer traços mórbidos, traços esses que condicionam as naturezas superiores. Num e noutro, a nevrose congênita que, em vez de produzir a degenerescência, é sublimada no gênio. Ela desenvolve neles, com a paixão do gênio e o dom de a expressar, o orgulho de seu estranhamento. Eles se sentem à parte, acima do vulgar pela chama que brilha neles [...]. Do fundo abismo, eles se elevam de um golpe de asa às regiões celestes, onde se identificam pelo culto do ideal e do amor puro aos seres de esplendor (CESTRE, 1934, p. 323).

O primeiro contato que Baudelaire teve com Poe foi através da leitura de "The Black Cat", traduzido por Isabelle Meunier e publicado em La Démocracie Pacifique (24 de janeiro de 1847). Logo após, numa carta a Théophile Thoré, o poeta não só se refere à forte impressão causada por Edgar Allan Poe, como também a uma coincidência temática e estilística entre ambos: "A primeira vez que abri um livro escrito por ele, vi com medo e prazer, não apenas temas sonhados por mim, mas frases pensadas por 
mim, escritas por ele vinte anos atrás" (1907, p. 362). Baudelaire publicou sua primeira tradução de Poe em 1848 - "Révélation Magnétique" saiu nas páginas de La Liberté de Penser. Em linhas gerais, Poe atraiu Baudelaire devido a uma afinidade espiritual muito intensa: o autor de Les Fleurs du Mal viu no escritor americano um predecessor, que antecipara certas novidades que só descobriria através do autor de "The Raven". Mas não só isso: como vimos na carta que Baudelaire dirigiu à mãe, ele disse que havia encontrado entre ambos uma fraternidade proveniente de uma existência sofrida. E é esse aspecto que o poeta francês irá destacar no primeiro dos prefácios que escreveu para as obras de Poe traduzidas e publicadas na França.

Esse prefácio, intitulado "Edgar Poe, Sa Vie et Ses Oeuvres", desenvolvimento de um artigo publicado na Revue de Paris (março-abril de 1852), saiu em 1856 com a tradução de Histoires Extraordinaires. O que chama a atenção nesse texto francamente biográfico (à exceção da IV parte, um pouco mais crítica), é, sobretudo, a "romanticização" de Poe. Baudelaire, numa linguagem melodramática e cheia de clichês, trata o escritor americano como uma vítima terrível do destino: "Existe pois uma Providência diabólica que prepara a infelicidade desde o berço, - que lança com premeditação as naturezas espirituais e angélicas nos meios hostis, como os mártires nos circos?". É nesse diapasão que Baudelaire reconstrói a vida do "pobre Eddie", chegando mesmo, num tour de force, a inventar subterfúgios para justificar certos deslizes de Poe, como o vício do álcool: "É natural, digo eu, supor que este poeta lançado tão criança nos acasos da vida livre, o cérebro solicitado por um trabalho rude e contínuo, buscasse às vezes uma voluptuosidade nas garrafas" (1962, p. 595 e 613). Verifica-se assim que o Poe visto por Baudelaire é um Poe de ficção, um Poe idealizado, fruto da rica imaginação de um dos maiores poetas da modernidade. O Poe que nasce das páginas exaltadas de Baudelaire é muito mais que o verdadeiro Poe, é o dandy satânico, um Roderick Usher lançado à vida, ultrajado pela sociedade utilitarista, que o rejeita e que é rejeitado pelo escritor, com o desprezo de uma existência aristocrática, vivida à margem dos bons costumes, à rebours dos honestos princípios burgueses.

Em síntese, de acordo com Barbey d'Aureville, Baudelaire "traduziu Poe duas vezes, na vida e na obra” (1951, p. 47). É só na quarta parte do ensaio que Baudelaire se aventura mais propriamente pela obra de Poe. Nesse fragmento do prefácio, destacam-se três pontos principais. $O$ primeiro deles trata do tópico que talvez mais tenha exercido atração em Baudelaire, o culto da Beleza pura: Poe conquistará a "admiração das pessoas que pensam, por seu amor ao Belo, por seu conhecimento das condições harmônicas da beleza"; o segundo deles trata de algo que constituirá a base da obra de Baudelaire, o grotesco: "o ardor com o qual ele se atira no grotesco pelo 
amor do grotesco e no horrível pelo amor ao horrível"; o terceiro deles trata das correspondências de alma entre as personagens de Poe e o meio em que vivem: "os cenários e acessórios são apropriados aos sentimentos das personagens [...]. A Natureza dita inanimada participa dos seres vivos e, como eles, estremece com um frêmito sobrenatural e galvânico" (BAUDELAIRE, 1962, p. 616, 623 e 617). Nada mais simbolista do que esta interpretação do espaço nos contos de Poe - Baudelaire, de certa forma, antecipa o conceito de "correlativo objetivo" cunhado por Eliot, ou seja, a expressão dos sentimentos através de imagens correspondentes da natureza.

O prefácio seguinte - "Notes Nouvelles sur Edgar Poe" - publicado com o segundo volume das obras de Poe, é bem mais consistente, embora, em parte, seja simples paráfrase dos textos teóricos do escritor americano e, em parte, uma adaptação das reflexões de Baudelaire sobre a arte. $O$ primeiro dos tópicos que o poeta francês chama a atenção é o desprezo do utilitarismo, ao afirmar que Poe, "no 'Colóquio entre Monos e Uma', despejou seu desprezo e seu desgosto sobre a democracia, o progresso e a civilização" (1962, p. 622). Baudelaire, na certa, referia-se à passagem em que Monos diz a Una: "e estes homens, os poetas, vivendo e perecendo no meio do desprezo dos "utilitaristas'” (POE, 1938, p. 445). Parece que o poeta francês exagerou ao se referir tanto à "democracia" quanto ao "progresso", ou se não exagerou, somou ao pensamento de Poe um próprio, aliás expresso com mais vigor ao longo de seus escritos. $O$ segundo dos tópicos diz respeito à perversidade humana, uma constante na obra de Poe. Baudelaire apaixonadamente investe contra os roussenianos, aqueles que acreditam na bondade inata do ser humano, os "reverenciadores da humanidade [...], todos esses bajuladores e enfadonhos que repetem em todas as variações possíveis de tom: 'nasci bom, e vós também, e todos nós nascemos bons'”. Esse talvez seja um dos pontos mais caros ao autor de Les Fleurs du Mal: o desprezo das teorias de Rousseau, ou melhor, de um elementar raciocínio à Pangloss. Para Baudelaire, a Natureza é má e só "produz monstros" (1962, p. 624 e 626). Ora, é essa concepção de feiúra intrínseca da Natureza que fez que Baudelaire acentuasse ainda mais o esteticismo que herdou de Poe. Desse modo, tanto para um quanto para outro, o artificial passa a ter mais valor que o natural. o Belo, em sua acepção mais ampla, só é atingido pela arte, com o auxílio da imaginação, que Baudelaire comenta na terceira parte do prefácio, vendo-a como um meio de perceber o "segredo das coisas, das correspondências, das analogias". Mais adiante, nesse mesmo prefácio, ao se referir à ineficácia da paixão, Baudelaire dá a entender que isso acontece porque ela é "natural, muito natural para não deixar de introduzir um tom ofensivo, discordante, no domínio da beleza pura" (1962, p. 630 e 636). 
$\mathrm{Na}$ IV parte do prefácio é que vamos encontrar o sumo das teorias poéticas de Poe, que Baudelaire abraça, não só parafraseando "The Poetic Principle" e "The Philosopy of Composition", mas também acrescentando tópicos de sua própria reflexão. $O$ valor da brevidade de um poema, o efeito da Beleza, o repúdio do Didatismo, da Paixão, da Inspiração e a apologia do intelecto, são os itens que Baudelaire comenta minuciosamente. À parte as ideias desenvolvidas por Edgar Allan Poe a que seria ocioso retornar, chama-nos a atenção a interpretação feita por Baudelaire da "intuição do belo", ou seja, a captação do belo na natureza, como um meio de aplacar a sede da Beleza de além-túmulo. Para Baudelaire, ela se traduz como "uma correspondência do Céu". Aqui, portanto, o que era simples paráfrase ganha contorno swedenborguiano, que já não é mais de Edgar Allan Poe, mas do próprio Charles Baudelaire: a poesia entendida como "correspondência", no sentido de que "cada coisa que existe, do mundo natural ao espiritual, é conhecida como correspondente” (SWEDENBORG, 1817, p. 68).

Outra ideia fundamental na poética de Baudelaire e que se encontra também na obra de Edgar Allan Poe é a de que a Beleza necessita de um pouco de deformidade para contrabalançar o excesso de harmonia. Poe, ao tratar da imaginação e da beleza extraída das deformidades, trata desse tópico da deformação em arte, tanto em "Marginalia" quanto na resenha dedicada a N.P. Willis, utilizando-se das mesmas palavras: "O alcance da imaginação é ilimitado. Seus utensílios estendem-se através do Universo. Mesmo das deformidades ela fabrica aquela Beleza que é imediatamente seu único objeto e sua inevitável experiência” (1938, p. 189). Baudelaire referenda as ideias de Poe, contudo vai um pouco mais adiante. Ele dá a entender que é possível extrair beleza até mesmo do que é disforme; aquele intensifica esta ideia, ao somar ao desejo, à aspiração da Beleza, também a aspiração, o desejo da deformidade:

Um artista não é senão um artista graças a um senso de refinado sentido de Beleza - sentido que lhe proporciona alegrias embriagadoras, mas que ao mesmo tempo implica, informa um sentido igualmente refinado de toda deformidade e de toda desproporção (BAUDELAIRE, 1962, p. 631-632).

A deformidade e/ou desproporção diz respeito à intuição do artista que, graças a ela, tem em alto grau um senso do disforme, o que sempre o leva a procurar a Beleza. Mas Baudelaire extrapola dessas considerações, na medida em que, num determinado momento, chega mesmo a dizer que $o$ Belo pode nascer do disforme, do desproporcional, tendo como resultado um efeito de estranhamento sobre o leitor, as mais das vezes acostumado com o excesso de harmonia. Em outro momento, ao tratar do refrão e da rima em 
Poe, Baudelaire comenta o efeito do estranhamento em poesia:

Do mesmo modo que demonstrara que o refrão é suscetível de aplicações infinitamente variáveis, ele também buscou rejuvenescer, redobrar o prazer da rima, acrescentando-lhe este elemento inesperado, a estranheza, que é como o condimento indispensável a toda a beleza (BAUDELAIRE, p. 637-638).

Nos Escritos Íntimos, Baudelaire (1982, p. 18) volta a tocar nesse mesmo ponto: "O que não é ligeiramente disforme se assemelha ao que é sensível: - donde se conclui que a irregularidade, quer dizer, o inesperado, a surpresa, o espanto são uma parte essencial e característica da beleza". Essa paradoxal aproximação entre o belo e o disforme está na base da obra poética de Baudelaire. A beleza disforme surge em Les Fleurs du Mal tanto de modo implícito quanto de modo explícito. No poema "Une Charogne", por exemplo, o senso do belo é extraído da exposição de uma carcaça corroída pelos vermes, ou no poema "Un Voyage à Cythère", em que o leitor é contemplado com a imagem de um enforcado devorado pelos corvos. Num dos prefácios que escreveu para o livro (edição de 1861), Baudelaire diz o seguinte: "Poetas ilustres partilharam desde muito tempo as províncias mais floridas do domínio poético. Me pareceu prazeroso e muito mais agradável, pois a tarefa era mais difícil, extrair a beleza do Mal" (1961, p. 248). O oximoro formado pela palavra "flor" (tradicionalmente sempre ligada ao Bem) e "mal" sugere uma arte em perene desequilíbrio, que serve para referendar, já ao nível do título, uma propensão para agregar a Beleza ao que é disforme.

A paráfrase dos princípios poéticos de Edgar Allan Poe levada a cabo por Baudelaire é um sinal eloquente da grande admiração que o poeta francês nutria pelo autor americano. Mas cremos que valeria a pena refletir um pouco mais sobre esse tópico das relações entre ambos, para evitar um erro comum da crítica que ora viu Baudelaire como simples epígono, ou mesmo como um plagiador de Poe (PATTERSON, apud CAMBIAIRE, 1927, p. 109), ora tentou localizar traços bastante visíveis das possíveis "correspondências" entre eles. E o caso, por exemplo, de C.H. Page (IBIDEM, p. 111), que percorre Les Fleurs du Mal apontando aqui e ali reflexos da obra poética de Poe, como neste cotejo de fragmentos de "Le Flambeau Vivant" e de "To Helen" (os grifos são nossos):

Ils marchent devant moi, ces Yeux pleins de lumières, Q'un Ange très savant a sans doute aimantés, Ils marchent, ces divins frères qui sont mes frères, Secouant dans mes yeux leurs feux diamantés. 
Me sauvant de tout piège et de tout péché grave, Ils conduisent mes pas dans la route du Beau; Ils sont mes serviteurs et je suis leur esclave; (BAUDELAIRE, 1961, p. 48)

$\mathrm{e}$

And thou, a ghost, amid the entombing trees Didst glide away, Only thine eyes remained. They would not go - they never yet have gone. Lighting my lonely pathway home that night, They have not left me (as my hope have) since.

They follow me -- they lead me through the years. They are my ministers -- yet I their slave.

(POE, 1992, p. 950).

Lavrière (apud CAMBIAIRE, 1927, p. 112), por sua vez, vê semelhança entre o verso "Mon coeur est un pays flétri par la cohue" ("Meu coração é um país manchado pela multidão") e os versos de "The Haunted Palace":

And travellers, now, within that valley,

Trough the pale door

A hideous throng rush out forever.

(POE, 1992, p. 959)

O próprio Cambiaire aproxima os versos de "Tableaux Parisiens" a versos de "Spirits of the Dead" e "The Sleeper" (1927, p. 113 et passim) e, na sequência do ensaio, acaba por se referir a vários críticos que encontraram semelhanças de ideia e forma entre ambos os escritores.

Mas não acreditamos que o melhor caminho para explicar as relações entre Poe e Baudelaire seja este - porque, se encontramos certas semelhanças bem visíveis (às vezes, a apropriação das palavras de um verso, às vezes, a apropriação de determinada ideia, a apropriação de um ritmo), também encontramos dessemelhanças, e são essas dessemelhanças que apontam para a especificidade de Baudelaire. As semelhanças, se exageradas, nos levariam a acreditar que Baudelaire seria apenas um epígono, um poeta menor. Mas o que aconteceu na realidade foi que Baudelaire ultrapassou seu modelo, pois sua poesia atinge um grau de complexidade que Poe jamais 
pôde atingir. A poesia do escritor americano ainda respira os últimos ares de um romantismo agonizante, e isso fica patente em seu extremado idealismo, em sua visão arcangélica e rarefeita da Natureza, da mulher e dos espaços celestiais. Mesmo nas narrativas em que o grotesco se acentua, as figuras femininas não deixam de ter estas características. Já Baudelaire é o poeta do Tédio supremo, dos abismos que se abrem, oferecendo a visão do Nada. Baudelaire é o poeta da "idealidade vazia", no dizer de Hugo Friedrich (1978, p. 47 a 49), ao contrário de Poe, que a preenchia com o recheio da Beleza platonicamente concebida. Baudelaire é o profeta da modernidade, franqueando ao leitor as portas que levam ao Desconhecido, ofertando-lhe uma inquietude perturbadora, um perfume doentio.

Um problema ainda se coloca, todavia: Baudelaire é com certeza um crítico e um poeta mais complexo do que Poe. Como entender que tenha aceitado in limine todas as afirmações, as ideias e mesmo toda a obra de Poe, não conseguindo ver (ou mesmo escamoteando) os seus defeitos? Podemos em parte concordar com Valéry, quando ele se refere à "troca de valores":

Baudelaire e Edgar Poe trocam valores. Cada um dá ao outro o que tem e recebe do outro o que não tem. Este último revela ao primeiro todo um sistema de novos e profundos pensamentos. Ele o esclarece, o fecunda, determina suas opiniões quanto a uma diversidade de temas: filosofia da composição, teoria do artificial, compreensão e condenação do moderno, importância do excepcional e de uma certa estranheza, atitude aristocrática, misticismo, o gosto pela elegância (1980, p. 137).

Mas essa ideia de "troca de valores" por si só não é suficiente para explicar as relações entre um mestre e um discípulo, que superou o próprio mestre, ainda mais se voltarmos a pensar que Baudelaire fechou os olhos para algumas das deficiências de Poe. No estudo sobre as aproximações entre Poe, Baudelaire e Mallarmé, P. Mansell Jones faz a seguinte afirmação: "o que até agora não foi explicado [...] é como um crítico da importância de Baudelaire pôde ter aclamado Poe como um perfeito artista e um homem de refinado gosto" (1951, p. 38-58). Jones ainda diz que Baudelaire, levado pela impulsividade, realizou uma "haute vulgarisation" de Poe. Em realidade, Baudelaire terminou por fazer uma idealização de Poe, como se ele fosse um alter ego, ou seja, se apelarmos para uma explicação psicológica elementar, diríamos que Baudelaire tinha dentro de si um modelo, uma ideia de poeta que gostaria de ser e, num esforço de despersonalização, projetou em Poe essa imagem ideal, criando um Edgar Poe superior aos poetas do tempo, tanto na vida quanto na obra. Esse "SuperPoe" é o refinado decadente, o artista do fim-de-século, um aristocrata, o protótipo do dandy, irmão solitário de Floressas des Esseintes, anti-herói do romance decadentista À Rebours, de 
Joris-Karl Huysmans. Poe seria, portanto, mais uma criatura de sonhos que Baudelaire incorporou e projetou para um mais além do que o Poe que viveu modestamente e morreu na miséria nos EUA.

Mas por que Edgar Allan Poe? Por que Baudelaire seguiu os passos de Poe e não os de Coleridge, Shelley ou mesmo Byron a quem também admirava? Numa primeira instância, acreditamos genericamente que houve entre ambos o que Mansell chama de "afinidade". Mas, além disso, seria possível pensar em duas hipóteses: a primeira fundada numa aproximação romantizada de Poe por parte de Baudelaire. É mais que evidente que o poeta francês sentiu enorme atração pela vida marginal (às vezes muito semelhante à sua, devido a um processo de deformação poética), pelo destino trágico, pela altiva isenção, pelos hábitos aristocráticos de um homem que vivia numa sociedade marcada pelo mercantilismo e pelo utilitarismo (o que não aconteceu a Coleridge, a Shelley e a Byron). A segunda hipótese é fundada de modo mais específico nas ideias, na teoria poética de Edgar Allan Poe. $O$ poeta americano talvez fosse para Baudelaire uma espécie de catalisador, um artista que, mesmo sem produzir uma obra de valor excepcional, teve $o$ condão de concentrar em si algo de fundamental que estivesse no ar e que estivesse disperso ou incubado em diferentes artistas do tempo. Assim, Poe representaria, aos olhos de Baudelaire, a quintessência do homo decadentis (em flagrante oposição ao homo faber da tradição norte-americana), ao pensar e divulgar, ao mesmo tempo, o culto à Beleza de Shelley, o desprezo ao didatismo de Coleridge, o controle das emoções e das paixões, o satanismo e o gosto da aventura de Byron. Baudelaire expressaria aqui o que Bloom cunhou de "anxiety of influence", a "description of poetic influence, or the story of intra-poetic relationships". Aceitando-se os princípios teóricos do crítico norte-americano, nesse caso de influência, veríamos, nessa relação Poe/Baudelaire, como "one poet helps to form another" (BLOOM, 1997, p. 5). No caso, Baudelaire expressa essa ansiedade de influência, ao se formar como escritor, tendo como parâmetro Edgar Allan Poe. Mas há um detalhe que nos chama atenção: o fato de a revisão feita por Baudelaire não levar em conta os defeitos do autor de "The Raven" ou mesmo tentar justificar seus vícios. Grandes poetas, diz-nos ainda Bloom, fazem sua história interpretando mal um outro, de modo a abrir espaço imaginativo para si próprios. Como bem observa Gleiton Lentz:

De fato, a renovação de valores poéticos iniciada pelo poeta das flores do mal, pode ser antecipada em virtude do exemplo e da influência da obra de Poe, mas também por este ter influído na evolução e nas articulações estéticas que ainda se desenvolviam na mente do jovem poeta francês. (2009, p. 531) 
Desse modo, não seria despropositado dizer que Poe talvez se constituísse num ente de ficção, num heterônimo, em que o poeta francês projetasse suas ânsias de uma arte refinada, voltada tão só para o mundo da Beleza. Em suma, o Poe que Baudelaire descobriu e revelou ao mundo, o Poe (poe)tizado por Baudelaire, às vezes, mais ficção que realidade, seria um ponto de partida, o estopim de uma complexa poética que viria modificar radicalmente não só a literatura francesa do século XIX, como também inaugurar a própria modernidade.

\section{REFERÊNCIAS}

BAUDELAIRE, Charles. Lettres de Baudelaire. Paris: Mercure de France, 1907.

. Baudelaire: a Self Portrait. Tradução e comentários de: HYSLOPE, L. B.; HYSLOPE JR., F. E. London: Oxford University Press, 1957.

Les Fleurs du Mal. Paris: Garnier, 1961.

. Curiosités Esthétiques, l’Art Romantique et Autres Oeuvres Critiques. Paris: Garnier, 1962.

Escritos Íntimos. Lisboa: Ed. Estampa, 1982.

BLOOM, Harold. The Anxiety of Influence. A Theory of Poetry. New York: Oxford University Press, 1997.

CAMBIAIRE, Célestin Pierre. The Influence of Edgar Allan Poe in France. New York: G. E. Stechert \& Co, 1927.

CESTRE, Charles. Poe et Baudelaire, Revue Anglo-Américaine, XI, p. 322-329, april, 1934.

FRIEDRICH, Hugo. Estrutura da Lírica Moderna. São Paulo: Duas Cidades, 1978.

JONES, P. Mansell. Poe and Baudelaire: the 'Affinity', Modern French Poetry. Cambridge: University Press, 1951.

LENTZ, Gleiton. Para uma poética da tradução: o ato de traduzir na crítica e no epistolário de Baudelaire. In: ENCONTRO NACIONAL DE TRADUTORES (ABRAPT), 10., 2009, Ouro Preto. Anais... Disponível em: <http://www.ichs.ufop.br/anaisdoentrad/images/stories/PDFs/42Lentz.pdf>. Acesso em: 6 mar. 2015.

PATTERSON, A. S. L'Influence d'Edgar Poe sur Charles Baudelaire, apud Célestin Pierre Cambiaire, The Influence of Edgar Allan Poe in France. New York: G. E. Stechert \& Co, 1927.

POE, Edgar Allan. Complete Tales and Poems. New York: The Modern Library, 1938.

Poe Desconhecido. Porto Alegre: L\&PM, 1980.

The Collected Tales and Poems of Edgar Allan Poe. New York: Modern Library Edition, 1992.

SHANKS, Edward. Edgar Allan Poe. London: MacMillan \& Co, 1937.

SWEDENBORG, Emanuel. A Treatise Concerning Heaven and its Wonders, and also Concerning Hell, 6. ed. London: E. Hodson: 1817.

VALÉRY, Paul. Sobre Poe, de Situação de Baudelaire. In: POE, Edgar Allan. Poe Desconhecido. Porto Alegre: L\&PM, 1980. p. 236-240.

WILSON, Edmund. O Castelo de Axel. 9. ed. São Paulo: Cultrix, 1993.

Submetido em: 01/04/2013

Aceito em: 10/12/2013

Revista Letras, Curitiba, N. 91 p. 5-15, JAN./JUN. 2015.

ISSN 2236-0999 (VERSÃo ELETRÔNICA) 